\title{
Effects of educational practices on the peritonitis risk in peritoneal dialysis: a retrospective cohort study with data from the French peritoneal Dialysis registry (RDPLF)
}

Hélène Bonnal ${ }^{1,2}$, Clémence Bechade ${ }^{1,2}$, Annabel Boyer ${ }^{1,2}$, Thierry Lobbedez ${ }^{1,3}$, Sonia Guillouët ${ }^{1}$, Christian Verger ${ }^{3}$, Maxence Ficheux ${ }^{1}$ and Antoine Lanot ${ }^{1,2^{*}}$ (D)

\begin{abstract}
Background: Peritoneal dialysis (PD) is a home-based therapy performed by patients or their relatives in numerous cases, and the role of patients' educational practices in the risk of peritonitis is not well assessed. Our aim was to evaluate the effect of PD learning methods on the risk of peritonitis.

Methods: This was a retrospective multicentric study based on data from a French registry. All incident adults assisted by family or autonomous for PD exchanges in France between 2012 and 2015 were included. The event of interest was the occurrence of peritonitis. Cox and hurdle regression models were used for statistical analysis to asses for the survival free of peritonitis, and the risk of first and subsequent peritonitis.
\end{abstract}

Results: 1035 patients were included. 967 (93\%) received education from a specialized nurse. Written support was used for the PD learning in 907 (87\%) patients, audio support in 221 (21\%) patients, and an evaluation grid was used to assess the comprehension in 625 (60\%) patients. In the "zero" part of the hurdle model, the use of a written support and starting PD learning with hands-on training alone were associated with a lower survival free of peritonitis (respectively HR $1.59,95 \% \mathrm{Cl} 1.01-2.5$ and HR $1.94,95 \% \mathrm{Cl} 1.08-3.49$ ), whereas in the "count" part, the use of an audio support and starting of PD learning with hands-on training in combination with theory were associated with a lower risk of presenting further episodes of peritonitis after a first episode (respectively HR $0.55,95 \% \mathrm{Cl} 0.31-$ 0.98 and HR $0.57,95 \% \mathrm{Cl} 0.33-0.96)$.

Conclusions: The various PD education modalities were associated with differences in the risk of peritonitis. Prospective randomized trials are necessary to confirm causal effect. Caregivers should assess the patient's preferred learning style and their literacy level and adjust the PD learning method to each individual.

Keywords: Educational practices, Health literacy, Patient education, Peritoneal dialysis, Peritonitis

\footnotetext{
* Correspondence: antoine.lanot@gadz.org

'Normandie Univ, UNICAEN, CUMR, CHU de Caen Normandie, Néphrologie,

Avenue de la cote de nacre, 14033 Caen-Cedex, France

${ }^{2}$ U1086 INSERM - ANTICIPE - Centre Régional de Lutte Contre le Cancer

François Baclesse, Caen, France

Full list of author information is available at the end of the article
}

C C The Author(s). 2020 Open Access This article is licensed under a Creative Commons Attribution 4.0 International License, which permits use, sharing, adaptation, distribution and reproduction in any medium or format, as long as you give appropriate credit to the original author(s) and the source, provide a link to the Creative Commons licence, and indicate if changes were made. The images or other third party material in this article are included in the article's Creative Commons licence, unless indicated otherwise in a credit line to the material. If material is not included in the article's Creative Commons licence and your intended use is not permitted by statutory regulation or exceeds the permitted use, you will need to obtain permission directly from the copyright holder. To view a copy of this licence, visit http://creativecommons.org/licenses/by/4.0/. The Creative Commons Public Domain Dedication waiver (http://creativecommons.org/publicdomain/zero/1.0/) applies to the data made available in this article, unless otherwise stated in a credit line to the data. 
ABREVIATIONS PDPeritoneal dialysis

CCIC harlson comorbidity index

RDPLF French Peritoneal Dialysis Registry

BMI Body mass index

CAPD Continuous ambulatory peritoneal dialysis

APD Automated peritoneal dialysis

\section{Background}

It is now well demonstrated that peritoneal dialysis (PD) delivers a high-quality treatment to patients presenting with end-stage renal disease. The survival of patients treated by PD is equivalent to the survival of those treated by hemodialysis, and several authors have shown that the technique is well tolerated and cost effective [1-3]. However, PD remains underused in several countries [4]. Peritonitis is a major cause of technique failure, and is one of the predominant factors limiting the extensive use of PD $[5,6]$. The rate of peritonitis is highly variable worldwide, and within countries [7-9]. The risk of peritonitis depends on non-modifiable factors (age, sex, diabetes) and modifiable factors (anti-infectious prophylaxis, catheter care, assistance for PD) [10, 11]. It is important to accurately analyze the effect of modifiable factors, since they are the most relevant to decreasing the rate of peritonitis [12]. To our knowledge, there is a lack of data regarding the role of patients' educational practices in the peritonitis risk [13]. Recommendations for PD training were proposed by the ISPD in 2016, but the adherence to these guidelines is probably far from optimal in France and worldwide [3, 14]. The objective of our study was to describe the educational practices proposed to French patients treated by PD and to evaluate the effect of these currently applied educational practices on the risk of peritonitis.

\section{Methods}

This was an observational retrospective study using data from the French Language Peritoneal Dialysis Registry (RDPLF). The registry includes several optional moduli, one of which is the "nurses' practices" modulus. Out of the 167 centers registered in the RDPLF, 94 participated to the "nurses' practices" modulus. All patients registered in the "nurses' practices" modulus of the RDPLF, starting PD between January 1, 2012 and December 31, 2015 were included in the study. The end of the observation period was December 31, 2016. Exclusion criteria were: assistance by nurse for PD exchanges, because the aim of the study was to assess the effect of educational practices dedicated to patients or their relatives, and age younger than 18 years when starting PD.

\section{Definition of variables}

\section{Individual characteristics}

Age at PD initiation, the number of new patients per year per center, sex, body mass index (BMI), diabetes mellitus, the causal nephropathy, the presence of illiteracy learning disability, manual disability, hearing or visual impairment were extracted from the registry. Comorbidities were assessed by calculating a modified Charlson score, which is the Charlson score after subtracting the age sub score, to evaluate the role of the comorbidities independently of the patient's age.

\section{Characteristics of centers and treatments}

PD modality (continuous ambulatory peritoneal dialysis (CAPD) or automated peritoneal dialysis (APD)), PD assistance (self-PD or family assisted PD), a previous treatment before PD initiation (hemodialysis, renal transplantation or no replacement therapy), and the administrative type of center (non-profit, general, university or private hospital) in which the patient was treated were listed.

\section{Educational practices}

Data about the educational practices used during the learning of $\mathrm{PD}$ of the patients were retrieved: the timing of the education regarding the catheter placement, whether the education had been provided by a nurse specialized in PD, the use of audio or written support for PD learning which was respectively an audio file, or a printed booklet given to the patient to learn about, the assessment of the patients' knowledge and skills concerning PD with an evaluation grid, defined as a standard list of items used for assessment of the patients' knowledge and skills concerning PD prior or after the learning courses (of note, standardized within each center but not between all centers), the use of standard theoretical courses or adapted theoretical courses (adapted to the presumed preferred learning style of patients), and the start of learning with theory or with hands-on training.

\section{Events of interest}

The number of peritonitis for each patient was retrieved, with the declared cause, and the responsible germs.

\section{Statistical analysis}

Categorical variables were described by proportion and percentage, and continuous variables were described by their median value and first and third quartile. Overlapping of different educational practices were presented using an upset diagram [15].

All statistical models were performed at the individual levels. The event of interest was the first peritoneal infection after the start of PD. A survival analysis with a Cox proportional hazard model was assessed, to estimate the association between the covariates and the risk of first peritonitis. The proportional hazard assumption was tested graphically by inspection of the Schoenfeld 


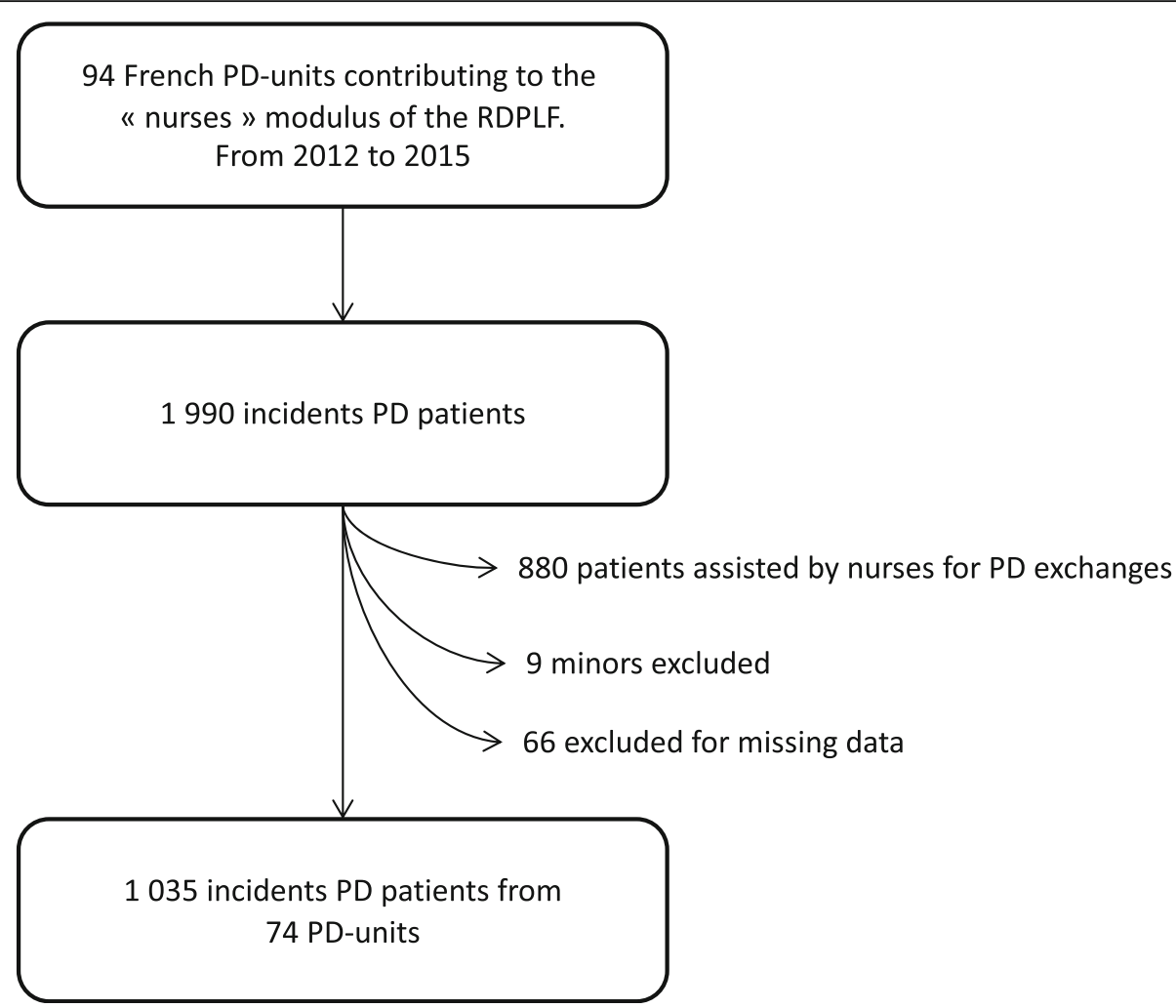

Fig. 1 Flowchart of the study

residual plots. The Cox model allows the assessment of the survival free of peritonitis, but does not consider the risks of multiples peritonitis cases. A classic Poisson regression model is commonly used to analyze count data, but it assumes that the number of patients with zero event is not overrepresented and that the variance of the distribution of the number of peritonitis cases is equal to the mean. Whenever these assumptions are violated, alternative models should be considered. Therefore, we used a hurdle model, which is built with two parts: a "zero count" rate ratio modeling the risk of presenting one peritonitis during the follow-up period, and a "count" rate ratio modeling the number of peritonitis during the follow-up period for the patients who have had a first episode. The exposure time to PD was used as an offset in both parts of the hurdle model.

Covariates associated with the risk of first peritonitis with $p<0.2$ in a bivariate analysis were entered in the multivariate analysis, and educational practices were entered a priori since they were the covariates of interest. The existence of collinearity between covariates was assessed by the generalized variance inflation factor.

In a sensitivity analysis, we assessed survival models focusing on the peritonitis due to handled germs (cocci Gram positive germs excluding Enterococcus and Streptococcus agalactiae), because this type of peritonitis is mainly due to contamination while handling PD fluid exchange, and therefore, good education should be associated with a lower risk.

To describe the distribution of the different practices in the centers, we arbitrarily chose a cut-off of $75 \%$ to decide whether a practice was standardized or not in the PD center. In other words, whenever a practice was used in more than $75 \%$ of the registered cases of the center, the practice was estimated standardized in the center. This value of $75 \%$ was chosen because it was estimated sufficient to make sure that whenever a practice was used $75 \%$ or more of the time in a given center, it would not be due to chance, but it would be a standard practice of the center. In the center-level analysis (and only in this analysis), 22 centers were excluded because fewer than 5 patients were registered. The center-level analysis was strictly descriptive, and no statistical tests were performed at the center-level.

Fewer than $10 \%$ of the data were missing in the dataset. Therefore, we performed a complete case analysis.

Statistical analyses were performed with $\mathrm{R}$ 3.5.1 (R foundation for statistical computing) including the survival and lme4 packages.

The RDPLF has the approval of the French National Ethics Committee (Commission nationale de l'informatique et des libertés) with the agreement number 542668 
Table 1 Population's characteristics

\begin{tabular}{|c|c|c|}
\hline & \multicolumn{2}{|c|}{ All patients $(\boldsymbol{N}=1035)$} \\
\hline Covariates & \multicolumn{2}{|c|}{ Median (IQR) } \\
\hline Age at PD initiation (years) & \multicolumn{2}{|c|}{$59(45-69)$} \\
\hline \multirow[t]{2}{*}{ BMI $\left(\mathrm{kg} / \mathrm{m}^{2}\right)$} & \multicolumn{2}{|c|}{$25(22-28)$} \\
\hline & $\mathbf{N}$ & $\%$ \\
\hline Sex (Male) & 667 & 64 \\
\hline Diabetes & 242 & 23 \\
\hline \multicolumn{3}{|l|}{ Nephropathy } \\
\hline Polycystic kidney disease & 124 & 12 \\
\hline Glomerulonephritis & 227 & 22 \\
\hline Systemic disease & 44 & 4 \\
\hline Diabetic nephropathy & 129 & 12 \\
\hline Interstitial nephritis & 60 & 6 \\
\hline Vascular & 198 & 19 \\
\hline Uropathy & 32 & 3 \\
\hline Other cause & 100 & 10 \\
\hline Unknown & 121 & 12 \\
\hline \multicolumn{3}{|l|}{ Previous treatment } \\
\hline No RRT & 770 & 74 \\
\hline Hemodialysis & 197 & 19 \\
\hline Transplantation & 19 & 7 \\
\hline PD modality (APD) & 628 & 61 \\
\hline \multicolumn{3}{|l|}{ Modality of PD assistance } \\
\hline Self PD & 937 & 91 \\
\hline Family assisted PD & 98 & 9 \\
\hline \multicolumn{3}{|l|}{ Type of center } \\
\hline General hospital & 487 & 47 \\
\hline Non profit & 260 & 25 \\
\hline University hospital & 181 & 17 \\
\hline Private & 107 & 10 \\
\hline \multicolumn{3}{|l|}{ Charlson's score } \\
\hline$<3$ & 487 & 47 \\
\hline 3 & 173 & 17 \\
\hline 4 & 130 & 13 \\
\hline$>4$ & 245 & 24 \\
\hline \multicolumn{3}{|l|}{ Functional impairment } \\
\hline No impairment & 857 & 83 \\
\hline Hearing impairment & 41 & 4 \\
\hline Visual impairment & 126 & 12 \\
\hline Hearing and visual impairment & 11 & 1 \\
\hline Manual disability & 46 & 4 \\
\hline Illiteracy & 14 & 1 \\
\hline Learning disability & 145 & 14 \\
\hline
\end{tabular}

$I Q R$ Inter-quartile range, $P D$ Peritoneal dialysis, $B M I$ Body mass index, $A P D$ Automated peritoneal dialysis and fulfills the GDPR requests. This study took place within the framework of this authorization. In the extracted dataset, information was anonymized by the RDPLF.

This study was reported in accordance with the Strengthening the Reporting of Observational Studies in Epidemiology (STROBE) guidelines [16].

\section{Results}

During the study period, there were 1990 incident PD patients registered in the "nurses' practices" modulus of the RDPLF, in 94 PD-units. A total of 880 patients were assisted by a nurse for PD exchange and were therefore excluded. Nine patients were excluded because they were under 18 years of age, and 66 were excluded because of missing data. Finally, data concerning 1035 patients from 74 PD units were analyzed (Fig. 1). The median follow-up time was 15.2 months. At the center level, the median number of incident PD patients per year was 5.6 (interquartile range (IQR) 3.4-9.4).

\section{Univariate analysis Study population}

The median age was 59 (IQR 45-69), and 667 (64\%) patients were male. Of the 1305 patients included, 937 (91\%) were autonomous and a family caregiver assisted 98 (9\%) patients. The three main causes of nephropathy were glomerulonephritis in 227 (22\%) patients, vascular nephropathy in 198 (19\%) patients, and diabetic nephropathy in 129 (12\%) patients. Two hundred and forty-two (23\%) patients were diabetic. The median BMI was $25 \mathrm{~kg} / \mathrm{m}^{2}$ (IQR 22-28). Seven hundred and seventy (74\%) patients were treated with neither dialysis nor renal transplantation before the PD initiation. One hundred and seventy-eight (17\%) patients presented deafness and/or visual impairment, and 145 (14\%) patients had learning disability. The characteristics of the population are displayed in (Table 1).

\section{Educational practices}

PD education was performed before catheter placement in 988 (95\%) patients, and PD education was provided by a specialized nurse in 967 (93\%) patients. The use of written support was widely spread in $907(88 \%)$ patients. Theory and hands-on training were proposed simultaneously to start PD education in $666(64 \%)$ patients. The distribution of educational practices at the patient's level is synthesized in (Table 2).

Table 2 also shows the distribution of educational practices standardly used at the center level (Table 2). A nurse specialized in PD provided the PD education to patients in every center. A written support was 
Table 2 Distribution of educational practices at the patient's level and at the center's level

\begin{tabular}{|c|c|c|c|c|c|}
\hline \multirow[t]{3}{*}{ Covariates } & & \multirow{2}{*}{\multicolumn{2}{|c|}{$\begin{array}{l}\text { All } \\
\text { patients } \\
(\mathbf{N}=1035)\end{array}$}} & \multirow{2}{*}{\multicolumn{2}{|c|}{$\begin{array}{l}\text { Number of centers } \\
(\boldsymbol{N}=53) \\
\text { Practice used in more than } 75 \% \text { of cases in } \\
\text { the center }\end{array}$}} \\
\hline & & & & & \\
\hline & & $\mathrm{N}$ & $\%$ & $\mathrm{~N}$ & $\%$ \\
\hline \multirow[t]{3}{*}{ Delay between education and catheter placement } & More than 30 days prior & 335 & 32.37 & 2 & 3.77 \\
\hline & Within 30 days & 653 & 63.09 & 17 & 32.07 \\
\hline & After catheter placement & 47 & 4.54 & 0 & 0 \\
\hline \multirow[t]{2}{*}{ Education provided by specialized nurse } & Yes & 967 & 93.43 & 48 & 90.57 \\
\hline & No & 68 & 6.57 & 1 & 1.89 \\
\hline \multirow[t]{2}{*}{ Use of a written support } & Yes & 907 & 87.63 & 42 & 79.25 \\
\hline & No & 128 & 12.37 & 3 & 5.66 \\
\hline \multirow[t]{2}{*}{ Use of an evaluation grid } & Yes & 625 & 60.39 & 26 & 49.06 \\
\hline & No & 410 & 39.61 & 16 & 30.19 \\
\hline \multirow[t]{2}{*}{ Use of an audio support } & Yes & 221 & 21.35 & 2 & 3.77 \\
\hline & No & 814 & 78.65 & 40 & 75.47 \\
\hline \multirow[t]{3}{*}{ Theory learning } & No & 14 & 1.35 & 0 & 0 \\
\hline & Standardized & 47 & 4.54 & 0 & 0 \\
\hline & Adapted & 974 & 94.11 & 47 & 88.67 \\
\hline \multirow[t]{3}{*}{ Education started with } & Theory & 269 & 25.99 & 5 & 9.43 \\
\hline & hands-on training & 100 & 9.66 & 1 & 1.88 \\
\hline & Both hands-on training and theory & 666 & 64.35 & 25 & 47.17 \\
\hline
\end{tabular}

A practice was arbitrarily defined as standardized in a given center if the practice was used in more than $75 \%$ of the registered cases of the center

standardly used in $42(79 \%)$ centers. Only two (4\%) centers used an audio support during the PD education of their patients. The more frequent association pattern of educational practices was the use of an evaluation grid, use of a written support, learning provided by a PDspecialized nurse, starting with adapted theory and hands-on training, and learning started within a month prior to catheter placement. The frequencies of these associations are depicted on the (Fig. 2).

\section{Characteristics of the peritonitis}

There were 565 episodes of peritonitis occurring in 339 patients. The peritonitis rate during the study period was 0.34 episodes per patient per year at risk. One hundred and sixty-three (48\%) peritonitis were due to Gram-positive cocci, and 80 (24\%) were due to Gram-negative bacilli. Causes were registered for the first peritonitis only. The major registered cause was asepsis mistake in 108 (31.86\%) cases of peritonitis, endogenous contamination in 47 (13.86\%) cases, tunnel infection in $11(3.24 \%)$ cases, mechanical issue in 11 (3.24\%) cases, and unknown in 145 (42.77\%) cases. Table 3 synthesizes the characteristics of peritonitis (Table 3). The proportions of peritonitis according to the educational practices are presented in
Table 4, according to the number of peritonitis: 0 , one or more than two (Table 4).

\section{Cox model \\ Bivariate analysis}

The results of the bivariate Cox model are shown in additional material (Additional file 1). The patient specific covariates that were significantly associated with the risk of peritonitis were: having a BMI between 25 and $30 \mathrm{~kg} / \mathrm{m}^{2}$ (HR 1.37, 95\%CI 1.08-1.74), and between 30 and $35 \mathrm{~kg} / \mathrm{m}^{2}$ (HR $1.56,95 \% \mathrm{CI}$ $1.10-2.22)$ compared to the class of reference 18 to $25 \mathrm{~kg} / \mathrm{m}^{2}$, having been treated with hemodialysis prior to PD compared to patients naive of prior extra renal epuration treatment (HR 1.48, 95\%CI 1.15-1.91), a modified Charlson's score equal to 3 compared with a score of 2 as the reference (HR 1.38, 95\%CI 1.04-1.83), and starting PD learning with hands-on training alone or in combination with theory (respectively HR 1.51, 95\%CI 1.02-2.23 and HR 1.29, 95\%CI 1.00-1.68). No significant association was retrieved between the risk of peritonitis and the other educational practices tested. The Kapplan Meier curve for peritonitis free survival is shown in (Fig. 3). 


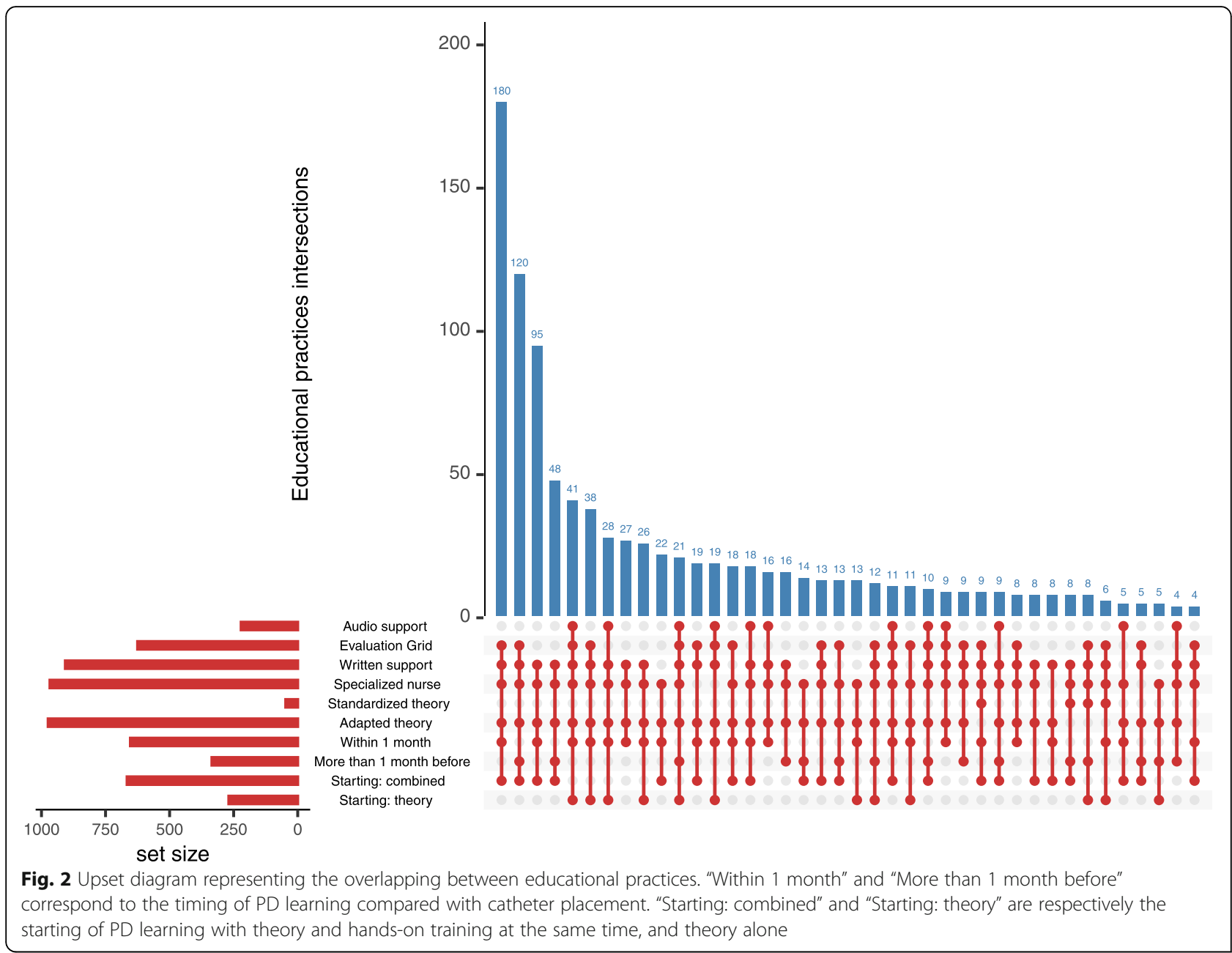

\section{Multivariate analysis}

The results of the Cox multivariate model are shown in (Fig. 4). Baselines covariates associated with a protective effect against peritonitis were being treated in a PD unit with ten or more incident patients per year ( $\mathrm{HR} 0.55,95 \% \mathrm{CI}$ $0.36-0.84$ ), presence of a hearing impairment (HR 0.35, 95\%CI 0.16-0.75). Some other covariates were associated with a higher risk of peritonitis: BMI comprised between 25 and $30 \mathrm{~kg} / \mathrm{m}^{2}$ (HR1.37, 95\%CI 1.07-1.75) or 30 and $35 \mathrm{~kg} /$ $\mathrm{m}^{2}$ (HR 1.51, 95\%CI 1.06-2.17), having been treated with hemodialysis prior to PD (HR 1.58, 95\%CI 1.21-2.05), and presenting a learning disability (HR 1.43, 95\%CI 1.05-1.95). Two educational variables were significantly associated with a higher risk of peritonitis: use of a written support (HR 1.44, 95\%CI 1.01-2.06) and starting education with handson training alone or combined with theory (respectively HR 1.6 95\%CI 1.04-2.46 and HR 1.34, 95\%CI 1.02-2.46).

\section{Hurdle model}

\section{Bivariate analysis}

In the "count" part of the hurdle model, starting PD between 30 and 49 years of age or between 50 and 64 years of age were associated with a higher risk of having further peritonitis after a first episode (respectively HR 5.13, 95\%CI 1.36-19.33, and HR 4.39, 95\%CI 1.1816.40). On the other hand, being treated in a center with ten or more new patients per year ( $\mathrm{HR} 0.36,95 \% \mathrm{CI}$ 0.14-0.97), having a BMI greater than $35 \mathrm{~kg} / \mathrm{m} 2$ (HR 0.04, 95\%CI 0-0.37), and starting PD learning with theory and hands-on training concomitantly were protective (HR 0.36, 95\%CI 0.14-0.92).

In the "zero" part of the hurdle model, male sex (HR 1.26 , 95\% CI 1.00-1.58), a BMI between 25 and 30 or between 30 and $35 \mathrm{~kg} / \mathrm{m} 2$ (respectively $\mathrm{HR} 1.34,95 \% \mathrm{CI}$ 1.05-1.71, and HR 1.59, 95\%CI 1.11-2.27), previous treatment by hemodialysis (HR 1.55, 95\%CI 1.19-2.01), a modified Charlson comorbidity index equal to 3 (HR 1.41, 95\%CI 1.05-1.89), and starting PD education with hands-on training alone or in combination with theory (respectively HR 1.64, 95\%CI 1.01-1.72 and HR 1.32, 95\%CI 1.10-2.45) were significantly associated with the risk of presenting a first episode of peritonitis, whereas hearing impairment was protective (HR 0.44, 95\%CI 0.21-0.93) (Additional file 2). 
Table 3 Characteristics of the peritonitis

\begin{tabular}{lll}
\hline & \multicolumn{2}{l}{ All patients $(N=1315)$} \\
\cline { 2 - 3 } Number of peritonitis & N \\
\hline 0 & 702 & 67.83 \\
1 & 207 & 20 \\
2 & 71 & 6.86 \\
3 & 31 & 3 \\
4 & 12 & 1.16 \\
5 or more & 12 & 1.16 \\
Type of germ for first peritonitis & & \\
Gram negative bacilli & 80 & 23.60 \\
Gram positive bacilli & 17 & 5.01 \\
Gram negative Cocci & 1 & 0.29 \\
Gram positive Cocci & 163 & 48.08 \\
Mycobacteria and unknown & 78 & 23.01 \\
Causes for first peritonitis & & \\
Asepsis mistake & 108 & 31.86 \\
Endogenous contamination & 47 & 13.86 \\
Mechanical issue & 11 & 3.24 \\
Tunnel infection & 11 & 3.24 \\
Cat & 6.59 \\
Nosocomial & 3 & 44.54 \\
Icodextrine & 151 & \\
Unknown & & \\
\hline & & \\
\hline
\end{tabular}

\section{Multivariate analysis}

After adjustment in the "count" part of the hurdle model, a BMI greater than $35 \mathrm{~kg} / \mathrm{m} 2$ (HR $0.11,95 \% \mathrm{CI}$ 0.01-0.96), a previous treatment by hemodialysis (HR $0.11,95 \%$ CI 0.01-0.96), use of an audio support for PD learning (HR 0.55, 95\%CI 0.31-0.98) and starting PD education concomitantly with both hands-on training and theory (HR $0.57,95 \% \mathrm{CI} 0.33-0.96$ ) were protective factors, whereas starting PD between 30 and 49 years of age (HR 3.2, 95\%CI 1.07-9.51) was associated with a higher risk of presenting further peritonitis after a first episode (Fig. 5).

In the "zero" part of the multivariate hurdle model, previous treatment by hemodialysis (HR 1.9, 95\%CI 1.33-2.73), a modified Charlson comorbidity index equal to 3 (HR 1.62, 95\%CI 1.08-2.42), learning disability (HR $1.56,95 \%$ CI 1.03-2.35), use of a written support for PD learning (HR 1.59, 95\%CI 1.01-2.5), and starting PD education with hands-on training (HR 1.94, 95\%CI 1.083.49) were significantly associated with the risk of presenting a first episode of peritonitis, whereas being treated in a center with ten or more new patient per year (HR 0.45, 95\%CI 0.26-0.77), and the presence of hearing impairment were protective (HR 0.29, 95\%CI 0.12-0.71) (Fig. 5).

\section{Sensitivity analysis}

One hundred and fifty-three peritonitis were due to handled germs. The results of the Cox multivariate analysis are shown in (Fig. 4). Starting PD education with handson training and theory at the same time was associated with a significantly higher risk of peritonitis due to manipulated germs (HR 1.58, 95\%CI 1.02-2.46).

\section{Discussion}

In this large observational study of patients autonomous or assisted by close relatives for PD care, we found that the use of a written support during PD learning and starting PD learning with hands-on training alone were associated with a lower survival free of peritonitis, whereas the use of an audio support and starting of PD learning with hands-on training in combination with theory were associated with a lower risk of presenting further episodes of peritonitis after a first episode.

PD is a home-based therapy; therefore, it is widely known that the patients and caregivers' education is essential to ensure a smooth running of the treatment. The best way to achieve this education is not well defined currently. However, several authors have tried to identify training methods to prevent peritonitis, and some protective factors have been pointed out. In Uruguay, Gadola et al. have shown that a PD education program based on the adult-learning principles was associated with a lower peritonitis rate $(0.29$ per patientyear vs 0.48 per patient-year with a previous PD education program, $p<0.05$ ) [17]. In a study from the Brazilian registry it was demonstrated that a cumulative training time greater than to $15 \mathrm{~h}$ was associated with significantly different peritonitis rates $(0.26$ per year at risk vs 0.32 per year at risk, $p=0.01)$ compared with a cumulative training time of less than $15 \mathrm{~h}$. Less than $1 \mathrm{~h}$ of training/day was associated with a higher incidence rate of peritonitis when compared with the intervals of $1-2 \mathrm{~h} /$ day $(p=0.03)$. Training in the immediate 10 days after implantation of the catheter was associated with the highest peritonitis rate compared with training prior to catheter implantation ( 0.32 per year vs 0.28 per year) [18]. The location of PD training could have an impact on peritonitis rates, according to the results from a monocentric Spanish study where the peritonitis incidence decreased from 1 episode $/ 24.5$ patient/month to 1 episode /44.4 patient/month after having implemented the training sessions in the patient's home [19]. Hsu et al. demonstrated that a multidisciplinary predialysis education was associated with a longer peritonitis free survival (HR 0.59, 95\%CI 0.43-0.81) [20]. 
Table 4 Proportion of peritonitis according to the different educational practice

\begin{tabular}{|c|c|c|c|}
\hline Number of peritonitis & $\begin{array}{l}0 \\
(\boldsymbol{N}=943)\end{array}$ & $\begin{array}{l}1 \\
(\boldsymbol{N}=236)\end{array}$ & $\begin{array}{l}2 \text { or more } \\
(\boldsymbol{N}=136)\end{array}$ \\
\hline \multicolumn{4}{|c|}{ Timing of education regarding catheter placement } \\
\hline More than 30 days prior to catheter placement & $225(32 \%)$ & $65(31 \%)$ & $45(36 \%)$ \\
\hline Within 30 days prior to catheter placement & $444(63 \%)$ & $132(64 \%)$ & 77 (61\%) \\
\hline After catheter placement & $33(5 \%)$ & $10(5 \%)$ & $4(3 \%)$ \\
\hline \multicolumn{4}{|l|}{ Education provider } \\
\hline Non-specialized nurse & $48(7 \%)$ & $13(6 \%)$ & $7(6 \%)$ \\
\hline Specialized nurse & $654(93 \%)$ & 194 (94\%) & 119 (94\%) \\
\hline Use of written support & $609(87 \%)$ & $182(88 \%)$ & $116(92 \%)$ \\
\hline Use of an evaluation grid & $424(60 \%)$ & $125(60 \%)$ & $76(60 \%)$ \\
\hline Use of audio support & $156(22 \%)$ & $40(19 \%)$ & $25(20 \%)$ \\
\hline \multicolumn{4}{|l|}{ Theory learning } \\
\hline No & $10(1 \%)$ & $3(1 \%)$ & $1(1 \%)$ \\
\hline Adapted learning & $660(94 \%)$ & 191 (92\%) & $123(98 \%)$ \\
\hline Standardized learning & $32(5 \%)$ & $13(6 \%)$ & $2(2 \%)$ \\
\hline \multicolumn{4}{|l|}{ First step of education } \\
\hline Theory & $194(28 \%)$ & $38(18 \%)$ & $37(29 \%)$ \\
\hline Hands-on training & $63(9 \%)$ & $26(13 \%)$ & $11(9 \%)$ \\
\hline Theory and hands-on training & $445(63 \%)$ & $143(69 \%)$ & 78 (62\%) \\
\hline
\end{tabular}

HR Hazard ratio, 95\% Cl 95\% Confidence interval, PD Peritoneal dialysis, BMI Body mass index, CAPD Continuous ambulatory peritoneal dialysis, APD Automated peritoneal dialysis

Learning PD theory and hands-on training can be challenging for some patients, and the PD learning programs should therefore be adapted to each patient. Several authors have shown that educational factors were associated with PD complications. In a large multicentric Brazilian observational study, Martin et al. showed that the patients' educational level was associated with the risk for survival free of peritonitis (illiteracy versus higher education level: HR 1.75, 95\%CI 1.04-2.92, elementary versus higher education level: $\mathrm{HR} 1.64$, 95\%CI $1.06-2.54$ and secondary versus higher education level: HR 1.57, 95\%CI: 0.99-2.49) [21]. An association between lower education level and the risk for peritonitis (HR $1.4595 \%$ CI 1.01-2.06, $p=0.0454$ ) was observed in a Taiwanese monocentric study in 2013 [22]. Kim et al. demonstrated similar results in a Korean population, where an education level of middle school or lower (academic year $<9$ ) was associated with a significant risk for peritonitis (HR 1.61, 95\%CI 1.10-2.36) [23]. Special attention could therefore be paid to the patients with lower education levels, who may need adapted learning styles. Assessing the knowledge and behavior in 191 Italian PD patients, Russo et al. found out that $47 \%$ of patients needed retraining, especially those in the early or late phase of PD therapy [24].

Congruently, we have found with the Cox model and the zero part of the hurdle model that hearing impairment was associated with a lower risk of presenting a first episode of peritonitis (respectively HR 0.35 , 95\%CI $0.16-0.75$ and $\mathrm{HR} \quad 0.29$, 95\%CI $0.12-$ 0.71 ). One might wonder how a disability could be protective. We make the hypothesis that in subjects with hearing impairments, the PD learning could be better individualized, with better adaptation to the abilities and learning patterns of the subjects. This protective effect however was not found in visual impaired patients, but it appears reasonable to think that a visual impairment is more disabling than a hearing one for realization of the PD exchange, due to the required dexterity.

The ISPD proposed recommendations for teaching PD to patients in 2016 [14]. These guidelines mainly advised basing the training programs on the principles of adult education, and proposed a five-day program of approximatively $3 \mathrm{~h}$ per day. Suggestions were made to assess the patient's preferred learning style and to implement teaching style accordingly. The use of the VARK (Visual, Auditory, Read and write, and Kinesthetic) learning style questionnaire was proposed.

To our knowledge, the effect of the teaching medium on PD learning has not been studied. We tried to assess the effect of using several educational supports on the risk of peritonitis. We found the use of a written support to be associated with a lower survival free of peritonitis. 


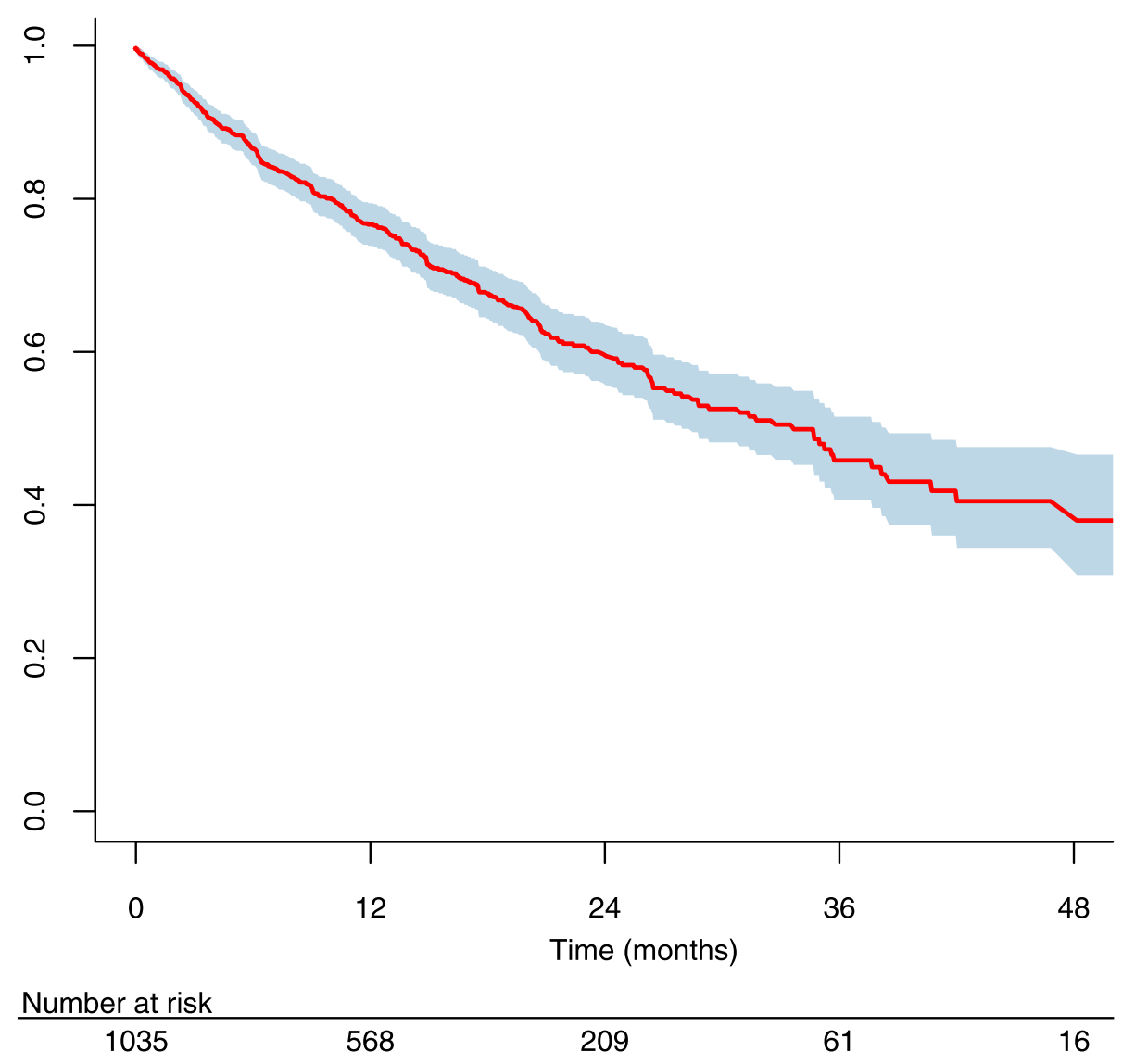

Fig. 3 Kaplan-Meier curve for peritonitis-free survival and 95\% confidence interval

It has been shown that the information materials aimed at patients with chronic kidney disease are above the average patient's literacy level, therefore many patients do not take advantage of the written supports provided, because they lack the skills required to understand them [25]. Moreover, we hypothesize that in some cases, written support may be provided to the patients with fewer explanations and/or fewer investments from the caring team in the learning process, therefore leading to poorer quality of the care. However, this result should be taken cautiously because it is not robust to the sensitivity analysis on handled germs peritonitis.

Patients who received audio support for PD learning experienced fewer recurrences after a first peritonitis episode. Notably, the use of audio support is not widespread in dialysis centers with only 2 centers using it as a standard feature, whereas written supports were used as standard features in 42 centers, as shown in Table 2. Therefore, we suppose that patients who benefit from audio learning may have been selected on some individual characteristics. This individualization of the educational support could be the explanation for this better outcome.
These results appear to be in line with the ISPD recommendations to assess the patient's preferred learning style and to plan the education accordingly. No support may be universally better for PD learning. PD training programs should contain different supports to be able to deliver the best education for each given patient.

Starting PD learning with hands-on training was associated with shorter survival free of peritonitis. The combination of hands-on training and theory were associated with a lower risk of further peritonitis after a first episode whereas it was nearly significantly associated with a higher risk for first episode in the "zero" part of the hurdle model. This phenomenon has been called a "dissonant effect" by Lachenbruch [26]. A telling example is considering an antibiotic treatment, that could be effective in reducing the risk of carrying some specific bacteria, whereas it could be associated with the growth of these bacteria after a first infection, due to antibiotic resistance. A possible explanation for the tendencies observed here could be that patients who started PD learning with hands-on training get more confident earlier with a risk of being less attentive to the rules of asepsis. After a first complication, they should become more cautious and present fewer recurrence. 


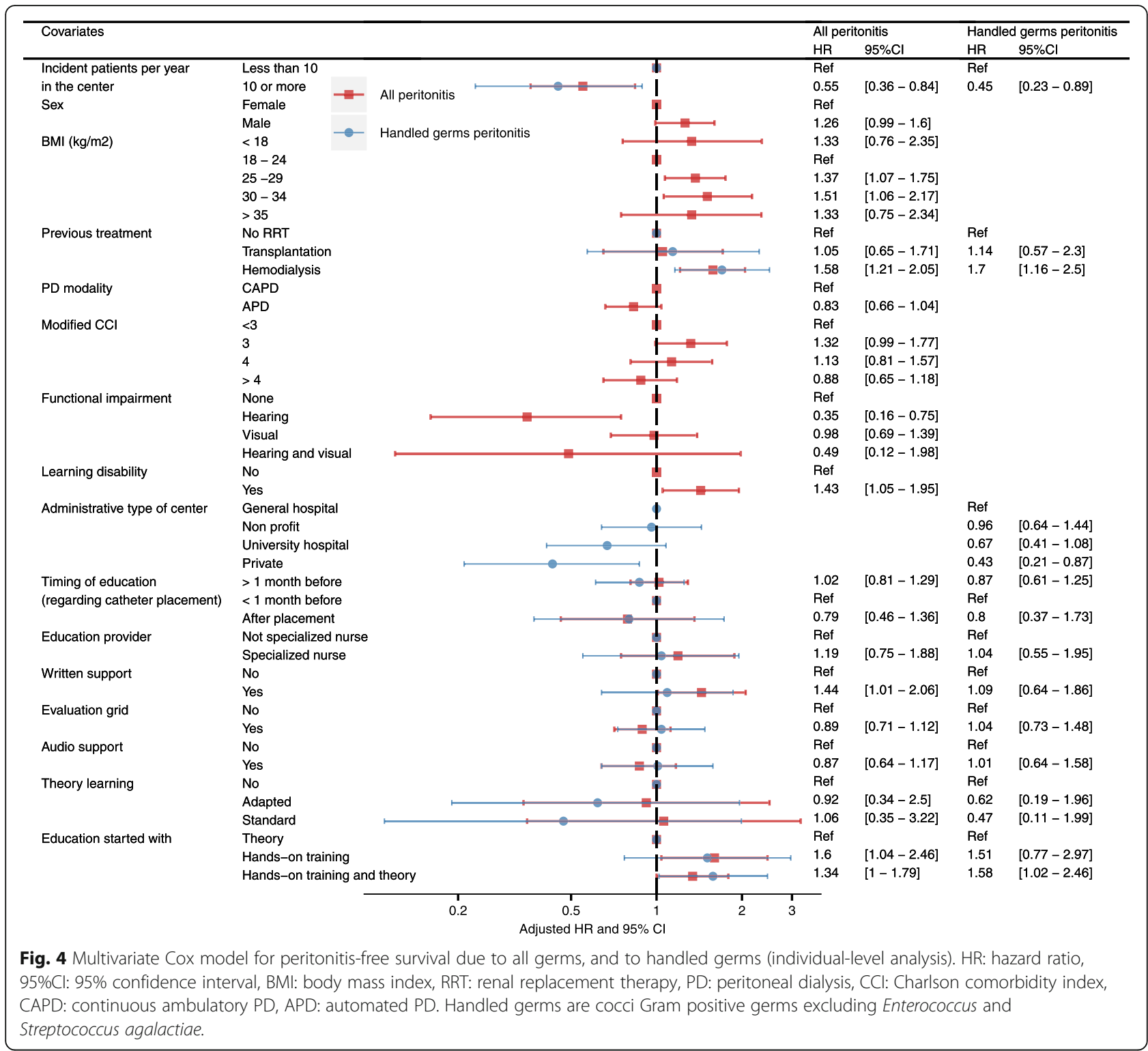

It is worth noticing that counterintuitively, in the "count" part of the multivariate hurdle model, BMI greater than $35 \mathrm{~kg} / \mathrm{m} 2$ was associated with a lower risk of presenting further peritonitis after a first episode. Obesity has been considered as a relative contra-indication to PD [27]. Therefore, we can hypothesize that nephrologists would be more likely to propose transfer to hemodialysis after a first peritonitis episode in obese patients, whereas they would have pursued the technique for non-obese patients. The protective effect against repeated peritonitis found here would in fact be biased by the presence of transfer to hemodialysis which is a competing event regarding peritonitis. This shorter time to transfer to hemodialysis therapy for obese patients has been reported in a 2017 American study [28].
Another worth commenting result was the higher risk for peritonitis of previous treatment by hemodialysis in the "zero" part of the multivariate hurdle model, whereas it was near significantly a protective effect in the "count" part. This dissonant effect can be explained by the fact that patients who experimented hemodialysis prior to PD might be transferred more easily than the others for several reasons: presence of a functional vascular access for hemodialysis, wish from the patient and/or the nephrologist to get back to a known dialysis modality. The lower survival risk free of peritonitis in patients previously treated with hemodialysis has already been found in a former study with data from the French registry, using a multivariate Cox model (cs-HR 1.15, 95\%CI 1.03-1.29) [29]. In a Polish study, Liberek et al. have shown that patients treated with hemodialysis prior to 


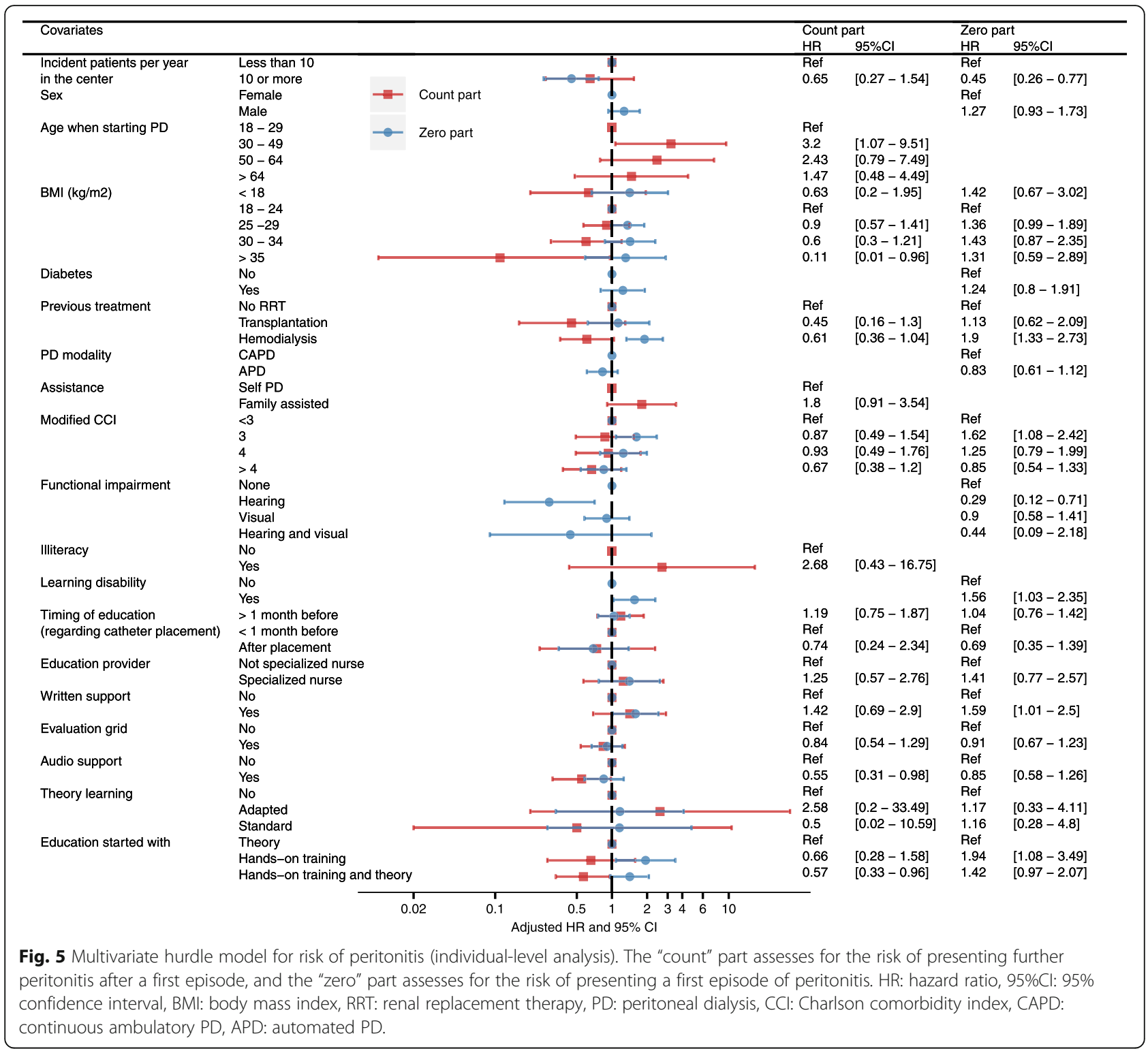

PD had a significantly higher peritonitis rate compared with those in whom PD was the initial method of renal replacement therapy ( 0.86 vs 0.62 episode per year, $p<$ 0.05) [30]. Patients are transferred from hemodialysis to PD because of complications such as vascular access problems, hemorrhage risk, or cardiovascular condition making hemodialysis no more pursuable. In such patients, PD is not the modality of choice so their involvement may be poorer, explaining the higher peritonitis risk.

Our study is genuine due to the covariates we studied. We assessed the effect of modifiable factors, which is always relevant because the results of the study may have clinical implications. We used quality data extracted from a nationwide registry known for its quality. These strengths should be balanced with some limitations.
Some bias may exist due to the retrospective type of the study. The population is not representative of the whole French PD population because some PD centers did not participate in the "nurses' practices" modulus in which the educational covariates were collected. Furthermore, we did not know how the methods of education for PD learning were chosen, which could have led to some selection bias. It would be of interest to assess and adjust the analysis on the educational and socioeconomic status of the patients, because these factors might interact with the educational method chosen and their effect.

\section{Conclusion}

We have found that the modality of PD learning was associated with the risk of peritonitis in autonomous or family assisted PD patients. The use of a written support 
and starting PD learning with hands-on training alone were associated with a lower survival free of peritonitis, whereas the use of an audio support and starting of PD learning with hands-on training in combination with theory were associated with a lower risk of presenting further episodes of peritonitis after a first episode. According to the ISPD guidelines, caregivers should assess the patient's preferred learning style and their literacy, to best adjust the PD learning program according to these preferences and skills, and offering individualized learning methods. Further interventional studies focusing on educational practices are needed to accurately determine the best practice in PD learning for patients.

\section{Supplementary information}

Supplementary information accompanies this paper at https://doi.org/10. 1186/s12882-020-01867-w.

Additional file $\mathbf{1}$ Table $\mathbf{1}$ Cox model for survival free of peritonitis. Bivariate analysis. Table showing the results of the bivariate Cox survival model for survival free of peritonitis.

Additional file $\mathbf{2}$ Table 2. Hurdle model for survival free of peritonitis. Bivariate analysis. Table showing the results of the bivariate hurdle model for the risk of peritonitis

\section{Acknowledgements}

We would like to express our gratitude to all nephrologists of the renal units who provided data to the RDPLF.

\section{Authors' contributions}

$\mathrm{HB}$ analyzed the data and drafted the work. CB designed the study and substantively revised the work. $A B$ substantively revised the work. TL designed the work and substantively revised the work.

SG substantively revised the work. CV acquired the data and provided intellectual content.

MF substantively revised the work. AL designed the study, analysed and interpreted the data, and drafted the manuscript. All authors have read and approved the manuscript.

\section{Funding}

No funding.

\section{Availability of data and materials}

The datasets used and analyzed during the current study are available from the corresponding author on reasonable request after approval obtained from the RDPLF.

\section{Ethics approval and consent to participate}

The RDPLF has the approval of the French National Ethics Committee (Commission nationale de l'informatique et des libertés) with the agreement number 542668 and fulfills the GDPR requests. This study took place within the framework of this authorization.

\section{Consent for publication}

Not applicable.

\section{Competing interests}

The authors declare that they have no competing interest.

\section{Author details}

${ }^{1}$ Normandie Univ, UNICAEN, CUMR, CHU de Caen Normandie, Néphrologie, Avenue de la cote de nacre, 14033 Caen-Cedex, France. ${ }^{2}$ U1086 INSERM ANTICIPE - Centre Régional de Lutte Contre le Cancer François Baclesse, Caen, France. ${ }^{3}$ RDPLF, 30 Rue Sere Depoin, 95300 Pontoise, France.
Received: 12 February 2020 Accepted: 25 May 2020

Published online: 29 May 2020

\section{References}

1. Wong B, Ravani P, Oliver MJ, Holroyd-Leduc J, Venturato L, Garg AX, et al. Comparison of patients survival between hemodialysis and peritoneal dialysis among patients eligible for both modalities. Am J Kidney Dis. 2018; 71:344-51.

2. Benain J-P, Faller B, Briat C, Jacquelinet C, Brami M, Aoustin M, et al. Cost of dialysis in France. Nephrol Ther. 2007;3:96-106

3. Boudville N, Cho Y, Equinox K-L, Figueiredo AE, Hawley CM, Howard K, et al. Teaching peritoneal dialysis in Australia: an opportunity for improvement. Nephrol. 2018:23:259-63.

4. Briggs V, Davies S, Wilkie M. International variations in peritoneal dialysis utilization and implications for practice. Am J Kidney Dis. 2019;74:101-110.

5. Fried L, Abidi S, Bernardini J, Johnston JR, Piraino B. Hospitalization in peritoneal dialysis patients. Am J Kidney Dis. 1999;33:927-33.

6. Wiggins KJ, Craig JC, Johnson DW, Strippoli GF. Treatment for peritoneal dialysis-associated peritonitis. Cochrane Database Syst Rev. 2008:CD005284.

7. Davenport A. Peritonitis remains the major clinical complication of peritoneal dialysis: the London, UK, peritonitis audit 2002-2003. Perit Dial Int. 2009:29:297-302.

8. Piraino B, Bernardini J, Brown E, Figueiredo A, Johnson DW, Lye WC, et al. ISPD position statement on reducing the risks of peritoneal dialysis-related infections. Perit Dial Int. 2011;31:614-30.

9. Ghali JR, Bannister KM, Brown FG, Rosman JB, Wiggins KJ, Johnson DW, et al. Microbiology and outcomes of peritonitis in Australian peritoneal dialysis patients. Perit Dial Int. 2011;31:651-62.

10. Nadeau-Fredette A-C, Bargman JM. Characteristics and outcomes of fungal peritonitis in a modern north American cohort. Perit Dial Int. 2015;35:78-84.

11. Béchade C, Guillouët S, Verger C, Ficheux M, Lanot A, Lobbedez T. Centre characteristics associated with the risk of peritonitis in peritoneal dialysis: a hierarchical modelling approach based on the data of the French language peritoneal Dialysis registry. Nephrol Dial Transplant. 2017;32:1018-23.

12. Mudge DW, Boudville N, Brown F, Clayton P, Duddington M, Holt S, et al. Peritoneal dialysis practice in Australia and New Zealand: a call to sustain the action. Nephrol. 2016:21:535-46.

13. Chow JSF, Cho Y, Equinox K-L, Figueiredo A, Frasca S, Hawley C, et al. An intervention design: supporting skills development for peritoneal Dialysis trainers. Perit Dial Int. 2019;39:134-41.

14. Figueiredo AE, Bernardini J, Bowes E, Hiramatsu M, Price V, Su C, et al. A syllabus for teaching peritoneal Dialysis to patients and caregivers. Perit Dial Int. 2016;36:592-605.

15. Lex A, Gehlenborg N, Strobelt H, Vuillemot R, Pfister H. UpSet: visualization of intersecting sets. IEEE Trans Vis Comput Graph. 2014;20:1983-92.

16. Von Elm E, Altman DG, Egger M, Pocock SJ, Gøtzsche PC, Vandenbroucke JP. The strengthening the reporting of observational studies in epidemiology (STROBE) statement: quidelines for reporting observational studies. J Clin Epidemiol. 2008;61:344-9.

17. Gadola L, Poggi C, Poggio M, Lungo E, Cardozo C. Risk factors and prevention of peritoneal dialysis-related peritonitis. Perit Dial Int. 2019;33:3845.

18. Figueiredo FG. Proença de Moraes T, Bernardini J, Poli-de-Figueiredo CE, Barretti $\mathrm{P}$, Olandoski $\mathrm{M}$ et al. on behalf of the BrazPD investigators. Impact of patients training patterns on peritonitis rates in a large national cohort study. Nephrol Dial Transplant. 2015;30:137-42.

19. Castro MJ, Celadilla O, Munoz I, Martinez V, Minguez M, Auxiliadora Bajo M, et al. Home training experience in peritoneal dialysis patients. EDTNA ERCA J. 2002;28:36-9.

20. Hsu CK, Lee CC, Chen YT, Ting MK, Sun CY, Hsu HJ, et al. Multidisciplinary predialysis education reduces incidence of peritonitis and subsequent death in peritoneal dialysis patients: 5-year cohort study. PLoS One. 2018;13: e0202781.

21. Martin LC, Caramori JCT, Fernandes N, Divino-Filho JC, Pecoits-Filho R, Barretti $P$, et al. Geographic and educational factors and risk of the first peritonitis episode in Brazilian peritoneal Dialysis study (BRAZPD) patients. Clin J Am Soc Nephrol CJASN. 2011;6:1944-51

22. Chern Y-B, Ho P-S, Kuo L-C, Chen J-B. Lower education level is a major risk factor for peritonitis incidence in chronic peritoneal dialysis patients: a retrospective cohort study with 12-year follow-up. Perit Dial Int. 2013:33: $552-8$. 
23. Kim HJ, Lee J, Park M, Kim Y, Lee H, Kim DK, et al. Lower education level is a risk factor for peritonitis and technique failure but not a risk for overall mortality in peritoneal Dialysis under comprehensive training system. PLoS One. 2017;12(1):e0169063.

24. Russo R, Manili L, Tiraboschi G, Amar K, De Luca M, Alberghini E, et al. Patient re-training in peritoneal dialysis: why and when it is needed. Kidney Int Suppl. 2006;70:S127-32.

25. Morony S, Flynn M, McCaffery KJ, Jansen J, Webster AC. Readability of written materials for CKD patients: a systematic review. Am J Kidney Dis. 2015;65:842-50

26. Lachenbruch PA. Comparisons of two-part models with competitors. Stat Med. 2001;20:1215-34.

27. NKF-DOQI clinical practice guidelines for peritoneal dialysis adequacy. National Kidney Foundation. Am J Kidney Dis. 1997;30:S67-136.

28. Obi Y, et al. Impact of obesity on modality longevity, residual kidney function, peritonitis, and survival among incident peritoneal dialysis patients. Am J Kidney Dis. 2017;71:802-13.

29. Guilloteau S, Lobbedez T, Guillouët S, Verger C, Ficheux M, Lanot A, Béchade C. Impact of assisted peritoneal dialysis on outcomes. Am J Nephrol. 2018:48:425-33.

30. Liberek T, Renke M, Skonieczny B, Kotewicz K, Kowalewska J, Chmielewski M, Kot J, Lichodziejewska-Niemierko M, Rutkowski B. Therapy outcome in peritoneal dialysis patients transferred from haemodialysis. Nephrol Dial Transplant. 2009:24:2889-94.

\section{Publisher's Note}

Springer Nature remains neutral with regard to jurisdictional claims in published maps and institutional affiliations.

Ready to submit your research? Choose BMC and benefit from:

- fast, convenient online submission

- thorough peer review by experienced researchers in your field

- rapid publication on acceptance

- support for research data, including large and complex data types

- gold Open Access which fosters wider collaboration and increased citations

- maximum visibility for your research: over $100 \mathrm{M}$ website views per year

At $\mathrm{BMC}$, research is always in progress.

Learn more biomedcentral.com/submissions 